\title{
Perimenopausal and Postmenopausal Complaints in Paramedics Assesed by Menopause Rating Scale in Indonesia
}

\author{
Muhammad Fidel Ganis Siregar ${ }^{1}$ \\ ${ }^{1}$ (Division of Reproductive Endocrinology and Fertility Medicine - Departemen of Obstetricss dan Gynecology \\ Faculty of Medicine - University of Sumatera Utara, Indonesia)
}

\begin{abstract}
:
Objective: To determine menopausal complaint proportions and discrepancies between perimenopausal and postmenopausal paramedics assesed using the menopause rating Scale.

Method: This analytical descriptive cross sectional study recruited perimenopausal and postmenopausal aged paramedics at Haji Adam Malik General Hospital and satelite hospitals, from which data were collected after filling several questionnaires. A total of 100 questionnaires each were distributed to the perimenopausal and postmenopausal group, the reults of which were assesed using the L-MMPI scale. The validity of this study was highly affected by honesty due to the subjective nature of the instruments used. Therefore, the L-MMPI scale is of great significance. Fifty subjects each were extracted from 60 perimenopausal and 58 postmenopausal eligible subjects with L-MMPI scores $<5$.

Results: Fourty seven perimenopausal (84\%) and 50 (100\%) postmenopausal subjects dominantly complained joint and muscular discomfort. Twenty two perimenopausal (22\%) women had mild somatic complaints, whereas 31 postmenopausal women (62\%) each reported mild somatic and severe urogenital complaints, respectively with a p-value of $<0.1$. Total complaint scores indicated that perimenopausal subjects dominantly had mild complaints (19 women, 38\%) whereas 35 subjects with moderate complaints dominated the post menopausal group (70\%), with a p-value of $<0.1$.

Conclusion: The proportion and severity degrees of menopausal symptoms significantly differed between perimenopausal and post menopausal paramedics
\end{abstract}

Keywords: Paramedics, Perimenopause, Postmenopause, Menopause Rating Scale

\section{I. introduction}

Menopause is defined as permanent menstrual cessation for 12 months or more, and is normally exerienced by middle aged women. Several menopausal complaints may day to day activities. Unfortunately, most women are unaware of certain menopausal changes. Resulting complaints are usually due to to decreasing estrogen levels in women near menopausal age. In several women, complaints may even emerge during early perimenopausal stages. ${ }^{1,2,3}$

Each year, 25 million women are predicted to enter the menopausal period worldwide. Also, globally, the amount of women aged 50 years would increase, from 500 million to more than 1 billion in 2030 (Hill, 1996). Based on WHO, in Asia, in 2025, the amount of advanced aged women would increase from 107 million to 373 million, due to the increased life expecntancy and more active post menopausal life style. ${ }^{4}$

Several studies have shown that perimenopausal and postmenopausal women more frerquently undergo menopausal complaints than premenopausal women, however, vasomotor, sexual, and psycological symptoms are more apparent in perimenopausal and post menopausal women than premenopausal. ${ }^{12,13}$ Health Department Guidelines, comprising comprehensive care for menopausal women, expains the ethical relationship between proffesional health providers and menopausal women, physiological and psychosocial phase and sexuality issues. However, an assumption that the practicing entirely based on this guidelines is not entirely mandatory, in which proffesional measures should adapt to real objective condition at hand, paramedics are still of great significance. $^{14}$

Based on how important the role of paramedics are in the management of menopausal patients, menopausal complaints in paramaedics should also be attended to. A study by MFG et al, in 2010 found that psycological complaints are more frequent in the post menopausal paramedic group compared to the perimenopausal group in which they more frequently complained anxiety (67,5\%), irritable (54,5\%), dan sleep difficulty $(50,6 \%) .{ }^{15}$

The Menopausal Rating Scale (MRS) is a qulatiy of life scale associated to health during the menopausal period, and was initially develiped in the $90 \mathrm{~s}$ to measure severity levels assoiciated with menopausal age, by assesing certain symptoms. ${ }^{18,19}$ To determine the extent of complaint and symptom experienced, factorial analysis and statistical methods were used to identify 3 symptom/complaint dimensions: 
psycological, somatic-vegetatif, and urogenital factors, that explain the $59 \%$ total variance, indicating the scale efficiency using only 11 items compared to other International scales. ${ }^{18,20}$

This study aimed on determining the proportion of perimenopausal and post menopausal complaints in paramedics, and whether there are any severity levels discrepancies between perimenopausal and post menopausal periods..

\section{Methods}

This analytical descriptive cross-sectional designed study, collected data from questionnaires filled perimenopausal and post menopausal women at Haji Adam Malik and Networking Hospitals of the Faculty of Medicine from November 2013 - December 2013 until a minimal amount of subjects were obtained.

Paramedic women aged $\geq 45$ years, serving at haji Adam Malik Hospital and Networking Hospitals during the above period, whom were menopausal for at least 12 consecutive months, underwent the L-MMPI (Minnesota Multiphasic Inventory Lie Scale) with a raw score $<5$, who volunteered to particpate, with no previous uterine or ovarian extracting procedures and did not receive any hormonal replacment therapy or contraceptive pills for the past 6 months, with no psyciatrical disorders and metastatic diseases, were included in this study.

Eligible subjects were interviewed from which age, parity, marital status, Last Menstrual Period, history of surigical procedures, academic degree, working unit, body weight and height, and history of contraceptive use, were noted.

The L-MMPI scale, an integrated part of the MMPI (Minnesota Multiphasic Personality Inventory) scale was then filled. The use of this scale was esstential, due to the sel rating of subjective nature of this study. Thus the validity of this study was highly affected by honesty in filling these instruments.

This scale has been used since 1949 Internationally in both the health and educational sectors. This scale comprises 15 questions that should be answered by either "Yes" or "No". The "raw score" was determined by the amount of "No" answers, at most 5 from 15. A raw score ecxceeded 5 indicated a dishonest tendency in answering the given questions, consequently excluding the subject.

Menopausal symtoms were measured using the Menopause Rating Scale (MRS), that comprised of 11 items to assess menopausal symptoms, and was divided into three subscales: (a) somatic - hot flushes, cardiac arrythmia, sleep disorders and muscle and joint issues (item 1-3 and 11), (b) psycological - depression, irritablility, anxiety and physical and irritablility, anxiety and physical and mental fatigue (item 4-7), and (c) urgenital bladder and vaginal dryness issues (item 8-10). Each item was assessable, from 0 (negative), until 4 ( $1=$ mild, $2=$ moderate, $3=$ severe, $4=$ very severe $)$.

The total score for each subscale was the amount of each item from each subscale. The total MRS was the total amount of each subscale.

Data were prossessed using a computer program from which data were presented in frequency distribution tables and narated descriptively. Intervariable analysis was perfomed using the chi-square with a $90 \%$ CI.

\section{Results}

Table 1 describes the charecteristics of samples based on age, from which all $45-50$ year aged women were still perimenopausal whereas $51-55$ year old women were generally menopausal $(90 \%)$. All subjects were married. Most of perimenopausal and post menopoausal women had a Diploma degree (52\% and 64\%, respectively).

Most perimenopausal and post menopausal women were multiparous (80\%). Thirty four percent of perimenopausal women each worked at the emergency room and wards, whereas $94 \%$ postmenopausal women worked at the ward. Most perimenopausal and post menopausal women were normoweight.

Table 2 described complaints experienced by perimenopausal and postmenopausal women from which perimenopausal women most frequently complained joint and muscle discomfort (84\%), depression and mood swings (68\%) and also physical and mental fatigue (68\%).

Post menopausal patients most frequently complained jont and muscle discomfort (100\%), sexual disorder issues (94\%), and vaginal dryness $(88 \%)$.

These results confirmed findings by Rahman A et al, in 2010 and a study by Chedraui P in 2007 in which joint and musccular discomfort was most frequently experienced $(80,1 \%)$

Most perimenopausal women complained depression and mood swings and also physical and mental fatigue, suitable to the findings by Rahman (2010). Urogenital complaints of sexual desires and vaginal dryness was dominant in postmenopausal women, also confirming results by Rahman (2010).

Table 3 shows that most perimenopausal women had less somatic complaints (44\%), whereas post menopausal mothers had mild complaints (62\%). Chi-square test obtained a p-value $<0,1$, indicating a signficant 
association between somatic complaints and menopausal status, also confirming the hypothesis proposing an association between somatic complaints and menopausal status.

Similar findings were reported by Chuni et al (2011), showing statistically higher somatic complaints in post menopausal women compared perimenopausal women.

\section{Discussion}

This study showed that classical complaints and sweating were found in $62 \%$ and $74 \%$ of perimenopausal and post menopausal women and confirmed findings from studies conducted in Europe with incidence rates for menopausal complaints such as hot flashes and sweating ranging $45 \%-75 \%$.

Somatic complaints, including hot flashes and night sweating, occur due to hormonal changes that consist of decreased or fluctuated levels of estrogen followed by increased FSH and LH levels. In most women, symptoms may persist for 1 to 2 years after menopause but, but may persist until ten years or more in other women.

Most perimenopausal (40\%) and post menopausal women $(60 \%)$ had mild psychological complaints. Chi-square test obtained a p-value $>0,1$, indicating an insignificant association between psychological complaints and menopausal status and consequently rejecting the hypothesis proposing that psychological complaints are significantly associated with menopausal status.

This contradicts findings by Chuni et al (2010) in which significantly differant psychological complaints were reported.

Whereas a study by Siregar et al (2010) showed no statistcally significant difference between depression and anxiety levels between the perimenopausal and postmenopausal group.

This is probably due to their academic degree and working enviroment, in which the menopausal procces and is understandable, and thus changes that occur due to the events are some what more acceptable. Literature also states that menopausal psycological complaints that occur are not absolutely attributed to hormonal changes, but also associated with physical, psychological, and health issues related with age.

In SWANS study, prevalence of mood disorders increase in premenopause to early perimenopause, about $10 \%$ to $16.5 \%$. Three possibilities could be proposed: (1) Decreases estrogen levels in menopause affecting mood-controlling neurotransmitters (2) mood affected by vasomotor syndrome (3) mood affected by life style alterations, usually occuring in menopausal women.

Perimenomausal women mostly complained mild urogenital symptoms (40\%), whereas postmenopausal women mostly complained severe symptoms (62\%). Statistic tests using Chi-square obtained a $\mathrm{p}$ value $<0,1$, indicating a significant association between urogenital complaints and menopausal status, consequently accepting the hypothesis proposing uruogenital complaints to be significantly associated with menopausal status.

Similar to findings by Dhillon et al (2006), a study by Rahman et al (2010) reported that post menopausal women more frequently had urogenital complaints in compared to perimenopausal women.

A study by Chuni (2011) concluded that urogenotal complaints are statistically higher in the post menopausal group $(80,6 \%)$ compared to the perimenopausal group $(77,2 \%)$.

Low Estrogen production in menopausal age may cause vaginal mucose atrophy, accompanied by vaginitis, prurity, dyspereunia, and stenosis. Estrogen loss can cause collagen loss, adipose tissue, and the ability to retain water. As the vaginal wall deteriotates, the rugae would smoothen and diminish. The epithelial surface would loose the fibrous outer surface and subsequently thinning to several cel layers, and decreased ratio between the superficial and basal cells. Consequently, the vaginal surface may be prone to bleeding with minimal trauma. Genitourinary atrohpy may affect quality of life, may cause dyspereunia and may cause decreased sexual desires.

The perimenopausal group mostly complained mild symptoms (38\%) whereas the postmenopausal group mostly consist of moderate symptoms $(70 \%)$. This indicated increased complaints in post menopausal women. Chi-square test obtained a $\mathrm{p}$-value $<0,1$, indicating a significant association between total complaint scores and menopausal status, thus confirming the hypothesis proposing a significant association between total complaint scores and menopausal status.

A study by Chuni et al (2010) concluded similar findings in which complaints, concluded based on the Menopause Rating Scale, were statistcally significantly higher in post menopausal and perimenopausal women.

Somatic and urogenital based complaints were statistically higher and significant in postmenopausal women compared to perimenopausal women.

\section{Conclusion}

The proportion and severity degrees of menopausal symptoms significantly differed between perimenopausal and post menopausal paramedics 


\section{References}

[1]. Williams RE, Levine KB, Kalilani L, Lewis J, Clark RV: Menopause-specific questionnaire assessment in US population-based study shows negative impact on health-related quality of life. Maturitas 2009, 62(2):153-9.

[2]. Lu J, Liu J, Eden J: The experience of menopausal symptoms by Arabic women in Sydney. Climacteric 2007, 10:72-7.

[3]. Rahman A, Zainudin S, Kar mun V. Assesment of Menopausal Symptoms Using Modified Menopause Rating Scale Among Middle Age Women in Kuching, Sarawak, Malaysia. Asia Pasific Family Medicine 2010,9:5.

[4]. WHO. Women and Health : Today's Evidence Tomorrow's Agenda. Depart of Reproductive Health and Research WHO, 2009.

[5]. Buckler H. The menopause transition: endocrine changes and clinical symptoms. J Br Menopause Soc 2005; 11:61-5.

[6]. Burger HG, Dudley EC, Robertson DM, Dennerstein L. Hormonal changes in the menopause transition. Recent Prog Horm Res 2002;57:257-75.

[7]. Malacara JM, Canto de Cetina T, Bassol S, et al. Symptoms at pre- and postmenopause in rural and urban women from three States of Mexico. Maturitas 2002;43:11-9.

[8]. Castelo-Branco C, Palacios S, Mostajo D, Tobar C, von Helde S. Menopausal transition inMovimawomen, a Bolivian NativeAmerican. Maturitas 2005;51:380-5.

[9]. Lee I, Wang HH: Pattern and related factors of self-care behavior among perimmenopausal women. Public Health Q 2001, 28:15160 .

[10]. Shanafelt TD, Barton DL, Adjei AA, Loprinzi CL: Pathophysiology and treatment of hot flashes. Mayo Clin Proc 2002, 77:12071218.

[11]. Fuh JI, Wang SJ, Lu SR, Juang KD, Chiu LM: The Kinmen women-health investigation (KIWI): a menopausal study of a population aged 40-54. Maturitas 2001, 39:117-24.

[12]. Jong LF, Shun JW, Shiang RL, Kai DJ, Lung MC: The Kinmen women-health investigation (KIWI): a menopausal study of a population aged 40-54. Maturitas 2001, 39:117-12.

[13]. Lori B, Crystal MS, Kavita N: Is This Women Perimenopausal. JAMA 2003, 289(7).

[14]. Limeria L, Geraldo F, Lima G, Braz E, Magalhoe O, Dacosta C. Assistence to Women In Menopause: Speech Of Nurses. J Nurs UFPE,7(1):665-71, Mar,2013.

[15]. Silitonga HN, Siregar MFG, Hutapea H, Nasution S. Depresi dan Cemas Masa Perimenopause dan Pascamenopause Pada Paramedis RSUP H Adam Malik dan RS Jejaring Medan. 2010.

[16]. Zollner YF, Acquadro C, Schaefer M. Literature review of instruments to assess health-related quality of life during and after menopause. Qual Life Res 2005;14:309-27.

[17]. Heinemann LAJ, Dominh T, Strelow F, Gerbsh S, Schnitker J, Schneider HPG. The Menopause Rating Scale (MRS) as outcome measure for hormone treatment? A validation study. Health Qual Life Outcomes 2004;2:67.

[18]. Chedraui P, Aguirre W, Hidalgo L, Fayad L. Assesing Menopausal Symptoms Among Healthy Middle Aged Women With The Menopausal Rating Scale. Maturitas 57,2007.271-278.

[19]. Potthoff P, Heinemann LAJ, Schneider HPG, Rosemeier HP, Hauser GA. Menopause-Rating Skala (MRS): Methodische Standardisierung in der deutschen Bev"olkerung. Zentralbl Gynakol 2000;122:280-6.

[20]. Heinemann K, Assmann A, M“ohner S, Schneider HPG, Heinemann LAJ. Reliabilit”at der Menopause-Rating-Skala (MRS). Untersuchung f ur die Deutsche Bev"olkerung. Zentralbl Gynakol 2002;124:161-3

[21]. Burger H, Dudley E, Robertson D, Dennerstein L. Hormonal Changes in Menopause Transition. The Endocrine Society, August 2005.

[22]. Goodman N, Cobin R, Ginzburg S, Katz I, Woode D. American Assiciation of Clinical Endocrinologist Medical Guidelines for Clinical Practice for The Diagnosis and Treatment of Menopause. Endocrine Practice,Vol.17. December 2011.

[23]. Baziad A. Menopause. Endokrinologi Ginekologi. Jakarta 2002.

[24]. Speroff L, Glass RH, Kase NG. Menopause and Postmenopausal Hormon Therapy. In Clinical Gynaecology Endocrinology and Infertility. Fifth Edition. William \& Wilkins, Baltimore-USA, 1994; 5 : 583-650

[25]. Jameson J. Hormonal Change in Menopause. Harrison's Endocrinology. McGraw Hill.2006.

[26]. Shifren, J.L., Schiff, I., 2007. Menopause. In: Berek, J.S., ed. Berek \& Novak's Gynecology. 14th ed. Stanford, California: Lippincott Williams \& Wilkins, 1324-1340.

[27]. Philp H. Hot Flashes, A Review of The Literature on Alternative and Complementary Treatment Approaches. Alternative Medicine Review. Vol 8, 2003.

[28]. Bachmann G. Vasomotor Flushes in Menopausal Women. Am J Obstet Gynecol 1999;180.

[29]. Albert K, Browell S. Estrogen, menopause, and mood regulation. Menopausal Medicine 2011.

[30]. Heinemann K, et al. The Menopause Rating Scale: A Methodological review. Health and Quality of Life Outcome 2004,2:45

[31]. Kakkar V, Chopra K, Kaur A, kaur I. Assesment of The Variation in Menopausal Symptoms With Age, Education and Working/non Working Status in North-Indian Subpopulation Using Menopause Rating Scale. Maturitas 57 (2007) 306-314.

[32]. Monterrosa A, Blumel J, Chedraui. Increased Menopausal Symptoms Among Afro Colombian Women as Assessed With The Menopause Rating Scale. Maturitas 59 (2008) 182-190.

Tables and Figures

Tabel 1. Sample Charecteristics

\begin{tabular}{|c|c|c|c|c|}
\hline \multirow[t]{2}{*}{ Charecteristics } & \multicolumn{2}{|c|}{ Perimenopause } & \multicolumn{2}{|c|}{ Postmenopause } \\
\hline & $\mathbf{N}$ & $\%$ & $\mathbf{N}$ & $\%$ \\
\hline \multicolumn{5}{|l|}{ Age (years) } \\
\hline 45-50 & 50 & 100 & 5 & 10 \\
\hline $51-55$ & $\mathbf{0}$ & $\mathbf{0}$ & 45 & 90 \\
\hline \multicolumn{5}{|l|}{ Marital Status } \\
\hline Married & 50 & 100 & 50 & 100 \\
\hline \multirow{2}{*}{ Not Married } & $\mathbf{0}$ & $\mathbf{0}$ & $\mathbf{0}$ & $\mathbf{0}$ \\
\hline & $\mathbf{0}$ & $\mathbf{0}$ & $\mathbf{0}$ & $\mathbf{0}$ \\
\hline \multirow{2}{*}{\multicolumn{5}{|c|}{$\begin{array}{c}\text { Widow } \\
\text { Academic degree }\end{array}$}} \\
\hline & & & & \\
\hline SPK & 5 & 10 & 10 & 20 \\
\hline Diploma & 26 & 52 & 32 & 64 \\
\hline
\end{tabular}




$\begin{array}{ccccc}\text { S1 } & 19 & 38 & 8 & 16 \\ \text { Amount of children } & & & & 2 \\ \text { Nuliparous } & 0 & 0 & 1 & 14 \\ \text { Primiparous } & 7 & 14 & 7 & 82 \\ \text { Multiparous } & 43 & 86 & 41 & 2 \\ \text { Grande multiparous } & 0 & 0 & 1 & \\ \text { Working unit } & & & & 28 \\ \text { ER } & 17 & 34 & 14 & \mathbf{3 2} \\ \text { Ward } & 16 & 32 & 16 & 40 \\ \text { Out patient clinic } & 17 & 34 & 20 & 44 \\ \text { IMT } & & 54 & 22 & 42 \\ \text { Normoweight } & 27 & 58 & 21 & 14 \\ \text { Overweight } & 19 & \mathbf{3 8} & 7 & 100 \\ \text { Obese } & 4 & \mathbf{5 0} & \\ \text { Amount } & 50 & 100 & & \end{array}$

Tabel 2. Description of Perimenopausal and Postmenopausal Complaints

\begin{tabular}{lcccc}
\hline & \multicolumn{2}{c}{ Complaints } & \multicolumn{2}{c}{ Postmenopausal } \\
& $\mathbf{N}$ & $\mathbf{\%}$ & $\mathbf{N}$ & $\mathbf{\%}$ \\
1.Hot flushes and sweat & 31 & 62 & 37 & 74 \\
2. Cardiac arrhythmia & 22 & 44 & 25 & 50 \\
3. Sleep Disorders & 30 & 60 & 29 & 58 \\
4. Depressed, mood swing & 34 & 68 & 35 & 70 \\
5. Irritable & 29 & 58 & 32 & 64 \\
6. Anxiety & 32 & 64 & 28 & 56 \\
7. Physical and mental fatigue & 34 & 68 & 32 & 64 \\
8. Sexual issues & 30 & 60 & 47 & 94 \\
9. Bladder and urinary tract issues & 11 & 22 & 37 & 74 \\
10. vaginal dryness & 7 & 14 & 44 & 88 \\
11. Joint and muscular discomfort & 47 & 84 & 50 & 100 \\
\hline
\end{tabular}

Tabel 3. Perimenopausal and Postmenopausal symptom Comparison

\begin{tabular}{|c|c|c|c|}
\hline & Perimenopausal & Postmenopausal & P-value \\
\hline \multicolumn{4}{|l|}{ Somatic complaints } \\
\hline - $\quad$ None or few $(0-2)$ & $22(44 \%)$ & $10(20 \%)$ & \\
\hline - $\quad$ Mild (3-4) & $16(32 \%)$ & $31(62 \%)$ & 0,008 \\
\hline - $\quad$ moderate (5-8) & $12(24 \%)$ & $9(18 \%)$ & \\
\hline \multicolumn{4}{|l|}{ Psycological complaints } \\
\hline - None or few $(0-1)$ & $11(22 \%)$ & $9(18 \%)$ & \\
\hline - $\quad$ Mild (2-3) & $20(40 \%)$ & $30(60 \%)$ & 0,205 \\
\hline - $\quad$ moderate (4-6) & $16(32 \%)$ & $10(20 \%)$ & \\
\hline - $\quad$ Severe $(\geq 7)$ & $3(6 \%)$ & $1(2 \%)$ & \\
\hline \multicolumn{4}{|l|}{ Urogenital complaints } \\
\hline - $\quad$ None or few $(0)$ & $16(32 \%)$ & $0(, 0 \%)$ & \\
\hline - $\quad$ Mild (1) & $20(40 \%)$ & $5(10 \%)$ & 0,0001 \\
\hline - $\quad$ moderate $(2-3)$ & $13(26 \%)$ & $14(28 \%)$ & \\
\hline - $\quad$ Severe $(\geq 4)$ & $1(2 \%)$ & $31(62 \%)$ & \\
\hline
\end{tabular}

